\title{
Evaluation of an inflammation-based prognostic score in patients with inoperable gastro-oesophageal cancer
}

\author{
ABC Crumley', DC McMillan*,', M McKernan', AC McDonald² and RC Stuart' \\ 'University Department of Surgery, Royal Infirmany, Glasgow G3I 2ER, UK; '² Beatson Oncology Centre, Western Infirmany, Glasgow GII 6NT, UK
}

\begin{abstract}
There is increasing evidence that the presence of an ongoing systemic inflammatory response is associated with poor outcome in patients with advanced cancer. The aim of the present study was to examine whether an inflammation-based prognostic score (Glasgow Prognostic score, GPS) was associated with survival, in patients with inoperable gastro-oesophageal cancer. Patients diagnosed with inoperable gastro-oesophageal carcinoma and who had measurement of albumin and C-reactive protein concentrations, at the time of diagnosis, were studied $(n=258)$. Clinical information was obtained from a gastro-oesophageal cancer database and analysis of the case notes. Patients with both an elevated C-reactive protein $\left(>|0 \mathrm{mg}|^{-1}\right)$ and hypoalbuminaemia $\left(<35 \mathrm{gl}^{-1}\right)$ were allocated a GPS score of 2 . Patients in whom only one of these biochemical abnormalities was present were allocated a GPS score of I, and patients with a normal C-reactive protein and albumin were allocated a score of 0 . On multivariate survival analysis, age (hazard ratio (HR) I.22, 95\% Cl I.02-1.46, P<0.05), stage (HR I.55, 95\% Cl I.30-1.83, $P<0.00$ I), the GPS $(\mathrm{HR}$ 1.5I, 95\% Cl 1.22-1.86, $P<0.00 \mathrm{I})$ and treatment (HR 2.53,95\% Cl I.80-3.56, $P<0.00 \mathrm{I})$ were significant independent predictors of cancer survival. A I2-month cancer-specific survival in patients with stage I/II disease receiving active treatment was 67 and $60 \%$ for a GPS of 0 and I, respectively. For stage III/IV disease, 12 months cancer-specific survival was 57,25 and I2\% for a GPS of 0,1 and 2, respectively. In the present study, the GPS predicted cancer-specific survival, independent of stage and treatment received, in patients with inoperable gastro-oesophageal cancer. Moreover, the GPS may be used in combination with conventional staging techniques to improve the prediction of survival in patients with inoperable gastro-oesophageal cancer.

British Journal of Cancer (2006) 94, 637-64I. doi:I0.1038/sj.bjc.6602998 www.bjcancer.com

Published online 14 February 2006

(c) 2006 Cancer Research UK
\end{abstract}

Keywords: gastro-oesophageal cancer; TNM stage C-reactive protein; albumin; survival

Gastro-oesophageal cancer is the third commonest cause of cancer death in the UK. Each year, there are approximately 16500 new cases and over 13000 deaths attributable to the disease. Overall survival is poor with the majority of patients presenting with advanced, inoperable disease and less than $15 \%$ surviving 5 years (Cancerstats, 2004; www.cancerresearchuk.org). Despite an often short median and poor overall survival, there is marked heterogeneity in the duration of survival among patients. Therefore, there is continuing interest in prognostic factors to permit more accurate patient stratification and which will improve clinical decision making, and possibly contribute to more rational study design and analysis (Allgayer et al, 1997).

A small proportion of patients with inoperable, but localised oesophageal cancers may be suitable for potentially curative nonsurgical treatment with (chemo) radiation therapy; however, most frequently, these modalities are used in palliation. While such palliative treatment may confer a small survival advantage over best supportive care, it is primarily directed towards symptom relief (Middleton and Cunningham, 1995; Pyrhonen et al, 1995). This however may sometimes be at the expense of toxicity (Ross

\footnotetext{
*Correspondence: Dr DC McMillan;

E-mail: d.c.mcmillan@clinmed.gla.ac.uk

Received 4 October 2005; revised 20 December 2005; accepted 17 January 2006; published online 14 February 2006
}

et al, 2002; Harvey et al, 2004) and therefore the appropriate selection of patients, most likely to benefit is of considerable importance.

Previous studies have indicated that weight loss or performance status may be associated with treatment outcome and survival in inoperable oesophago-gastric cancer (Andreyev et al, 1998; Chau et al, 2004). However, the use of weight loss as a prognostic factor remains problematical since it is often not well defined and subject to bias (Morgan et al, 1980; Rowland, 1990). Furthermore, performance status is recognised to be subjective (Ando et al, 2001)

There is increasing evidence that the presence of a systemic inflammatory response, as evidenced by elevated concentrations of C-reactive protein, is a prognostic factor independent of stage, performance status and weight loss in patients with advanced cancer (O'Gorman et al, 2000; Scott et al, 2002; Maltoni et al, 2005). Recently, we have shown that an elevated C-reactive protein and hypoalbuminaemia (using standardised assays and accepted thresholds for C-reactive protein and albumin concentrations) may be combined to form a score, the Glasgow Prognostic score (GPS), which has prognostic value, independent of stage and performance status, in patients with inoperable non-small-cell lung cancer (Forrest et al, 2003, 2004).

The aim of the present study was to assess the relationship between the GPS and survival in patients with inoperable gastrooesophageal cancer. 


\section{MATERIALS AND METHODS}

\section{Patients}

Patients diagnosed with inoperable gastro-oesophageal carcinoma, attending the upper GI surgical unit in the Royal Infirmary, Glasgow between the 1 January 2000 and the 31 December 2004 and who had a pretreatment measurement of C-reactive protein and albumin were studied. Patients were staged using a combination of endoscopy, CT scan of chest and abdomen, laparoscopy and endoscopic ultrasound, in addition to clinical assessment. The specific use of these modalities was dependent upon the clinical tumour features and where appropriate, assessment of fitness, cardiac and lung function testing was also performed.

The extent of tumour spread was recorded using the TNM stage. Tumours around the gastro-oesophageal junction were further classified according to site, using the Siewert system; type 1 and 2 lesions of the gastro-oesophageal junction were designated as cancers of the oesophagus. Type 3 tumours of the cardia were designated as gastric cancers.

Patients identified as being suitable for resection or radical, nonsurgical treatment given with curative intent were excluded from this analysis, as were patients who had any form of chronic inflammatory disease (e.g. vasculitis, connective tissue disorders, rheumatological conditions) and those with cancers arising in other organs. Therefore, the study group comprised patients unsuitable for either surgical resection or radical, nonsurgical treatment.

Patients who underwent palliative chemotherapy, palliative radiotherapy or endoscopic laser were considered to have had 'active' treatment. Patients receiving palliative care (symptom control) were considered to have had 'supportive' treatment. The 'active' treatment group was further subdivided into: chemotherapy based (chemotherapy \pm radiotherapy \pm endoscopic treatment), radiotherapy based (radiotherapy \pm endoscopic treatment) and endoscopic laser (laser \pm stent).

The study was approved by the Research Ethics Committee of Glasgow Royal Infirmary.

\section{Methods}

Routine laboratory measurements of C-reactive protein and albumin at the time of diagnosis were carried out. The limit of detection of the $\mathrm{C}$-reactive protein assay was $<6 \mathrm{mgl}^{-1}$. The coefficients of variation of these methods, over the range of measurements, was less than $5 \%$ as established by routine quality control.

The GPS was constructed as previously described (Forrest et al, 2003, 2004). Briefly, patients with both an elevated C-reactive protein $\left(>10 \mathrm{mgl}^{-1}\right)$ and hypoalbuminaemia $\left(<35 \mathrm{gl}^{-1}\right)$ were allocated a score of 2 . Patients in whom only one of these biochemical abnormalities was present were allocated a score of 1 . Patients in whom neither of these abnormalities was present were allocated a score of 0 .

\section{Statistics}

Data are presented as median and 95\% CI. Grouping of the variables was carried out using standard thresholds. Univariate survival analysis was performed using the Kaplan-Meier method with the logrank test. Multivariate survival analysis and calculation of hazard ratios (HR) were performed using a Cox regression model including all covariates that were significant on univariate analysis. Deaths up to 30 June 2005 were included in the analysis. Analysis was performed using SPSS software (SPSS Inc., Chicago, IL, USA).

\section{RESULTS}

The characteristics and survival analysis of patients with inoperable gastro-oesophageal cancer $(n=258)$ are shown in Table 1 .
Table I Clinical characteristics and cancer-specific survival in patients with inoperable gastro-oesophageal cancer: univariate survival analysis

\begin{tabular}{|c|c|c|c|}
\hline & $\begin{array}{l}\text { Patients } 258 \\
\text { (100\%) }\end{array}$ & $\begin{array}{c}\text { Survival } \\
\text { (months) } \\
\text { median }(95 \% \mathrm{Cl})\end{array}$ & $P$-value \\
\hline \multicolumn{4}{|l|}{ Age (years) } \\
\hline $\begin{array}{l}<65 \\
65-74\end{array}$ & $\begin{array}{l}91(35) \\
64(25)\end{array}$ & $\begin{array}{l}8.0(7.0-9.0) \\
66(25-10.8)\end{array}$ & \\
\hline$>75$ & $103(40)$ & $7.4(4.8-10.1)$ & 0.664 \\
\hline \multicolumn{4}{|l|}{ Sex } \\
\hline Male & $166(64)$ & $7.4(5.7-9.1)$ & \\
\hline Female & $92(36)$ & $8.0(6.2-9.9)$ & 0.728 \\
\hline \multicolumn{4}{|l|}{ Tumour type } \\
\hline Adenocarcinoma & 187 (73) & $8.2(6.2-9.6)$ & \\
\hline Squamous & 7I (27) & $6.6(4.9-8.3)$ & 0.979 \\
\hline \multicolumn{4}{|l|}{ Tumour site } \\
\hline Oesophagus & $142(55)$ & $8.9(6.8-\mid 1.1)$ & \\
\hline Gastric & $116(45)$ & $6.6(4.0-9.3)$ & 0.042 \\
\hline \multicolumn{4}{|l|}{ TNM stage } \\
\hline I & $29(11)$ & $20.5(13.3-27.7)$ & \\
\hline$\|$ & $27(11)$ & $11.8(8.3-15.3)$ & \\
\hline III & $64(25)$ & $9.8(8.1-11.5)$ & \\
\hline IV & $138(53)$ & $4.5(2.4-6.5)$ & $<0.001$ \\
\hline \multicolumn{4}{|c|}{ Alkaline phosphatase $\left(U I^{-1}\right)$} \\
\hline $\begin{array}{l}\text { Tertile । } \\
(n=85)\end{array}$ & $145(19-176)^{\mathrm{a}}$ & $8.4(6.7-10.2)$ & \\
\hline $\begin{array}{l}\text { Tertile } 2 \\
(n=85)\end{array}$ & $199(176-233)$ & $8.9(6.8-\mid 1.1)$ & \\
\hline $\begin{array}{l}\text { Tertile } 3 \\
(n=84)\end{array}$ & $325(235-2396)$ & $5.0(2.1-7.9)$ & 0.050 \\
\hline \multicolumn{4}{|l|}{ GPS } \\
\hline 0 & $92(36)$ & | $3.6(9.2-18.1)$ & \\
\hline I & 121 (47) & $6.3(4.2-8.5)$ & \\
\hline 2 & $45(17)$ & $2.4(0.5-4.4)$ & $<0.001$ \\
\hline \multicolumn{4}{|l|}{ Treatment } \\
\hline Active & $195(76)$ & $10.1(8.6-11.6)$ & \\
\hline Supportive & $63(24)$ & $2.1(1.3-2.8)$ & $<0.001$ \\
\hline
\end{tabular}

Median (range). GPS = Glasgow Prognostic score.

The majority were male, over the age of 65 years, had stage IV disease and had tumours of the oesophagus. Patients with stage I and II disease were not considered suitable for surgery or radical chemoradiation due to comorbidity. The majority of patients had an abnormal GPS. Of the 52 patients with hypoalbuminaemia, $45(86 \%)$ had an elevated C-reactive protein concentration. In total, 195 patients $(76 \%)$ received active treatment and the remainder received supportive care only.

The minimum follow-up was 6 months or until date of death; the median follow-up of the survivors was 12 months. During this period, $211(82 \%)$ patients died: 202 patients of their cancer and nine of intercurrent disease. On univariate analysis, tumour site $(P<0.05)$, stage $(P<0.001)$, alkaline phosphatase $(P<0.05)$, the GPS $(P<0.001$, Figure 1$)$ and treatment $(P<0.001)$ were significant predictors of cancer-specific survival. On multivariate analysis, age $(P<0.05)$, stage $(P<0.001)$, the GPS $(P<0.001)$ and treatment $(P<0.001)$ were significant independent predictors of cancerspecific survival (Table 2).

The characteristics and survival analysis of those patients receiving active treatment $(n=195)$ are shown in Table 3 . On multivariate analysis, stage $(P<0.001)$, the GPS $(P<0.001$, 
Figure 2) and treatment $(P<0.01)$ were significant independent predictors of cancer-specific survival.

The characteristics and survival analysis of those patients receiving supportive treatment $(n=63)$ are shown in Table 4 . On multivariate analysis, only stage $(P<0.05)$ was a significant independent predictor of cancer-specific survival.

The relationship between stage, the GPS and the 12-month survival rate in those patients receiving active treatment is shown in Table 5. The 12-month cancer-specific survival in patients with stage I/II disease receiving active treatment was 67 and $60 \%$ for a GPS of 0 and 1, respectively. For stage III/IV disease, the 12-month cancer-specific survival was 57,25 and $12 \%$ for a GPS of 0,1 and 2, respectively.

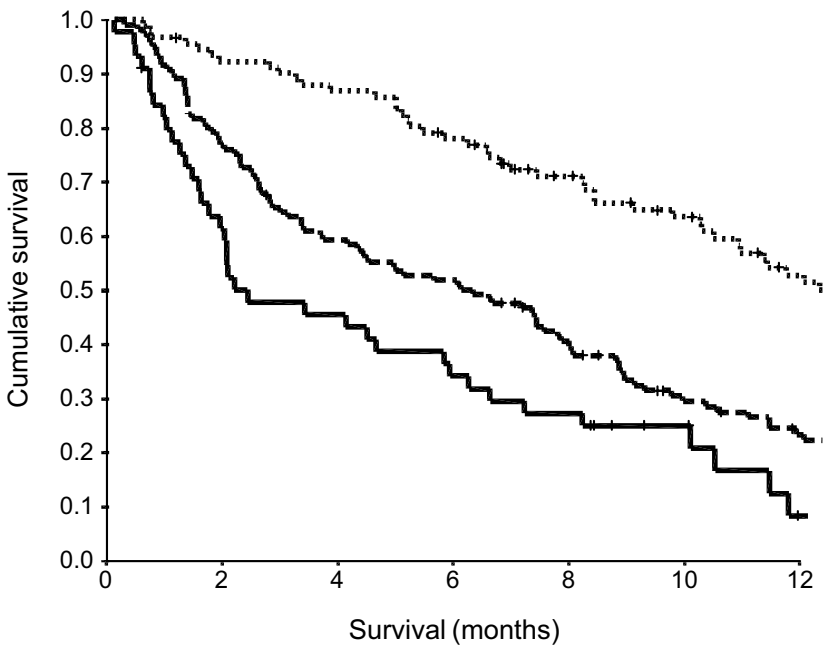

Figure I The relationship between an inflammation-based prognostic score (GPS, 0, I, 2 from top to bottom) and survival in patients with inoperable gastro-oesophageal cancer.

\section{DISCUSSION}

In the present study the presence of a systemic inflammatory response, reflected in the GPS, predicts cancer-specific survival, independent of tumour stage, in patients with inoperable gastrooesophageal cancer. Moreover, we have shown how the GPS might be used in combination with stage to improve the prediction of survival. It may be that this simply derived inflammation-based score will be a useful tool in the prediction of survival and possible stratification, at diagnosis, of patients with inoperable gastrooesophageal cancer.

It was of interest that, in the present study, only seven (14\%) patients had hypoalbuminaemia in the absence of an

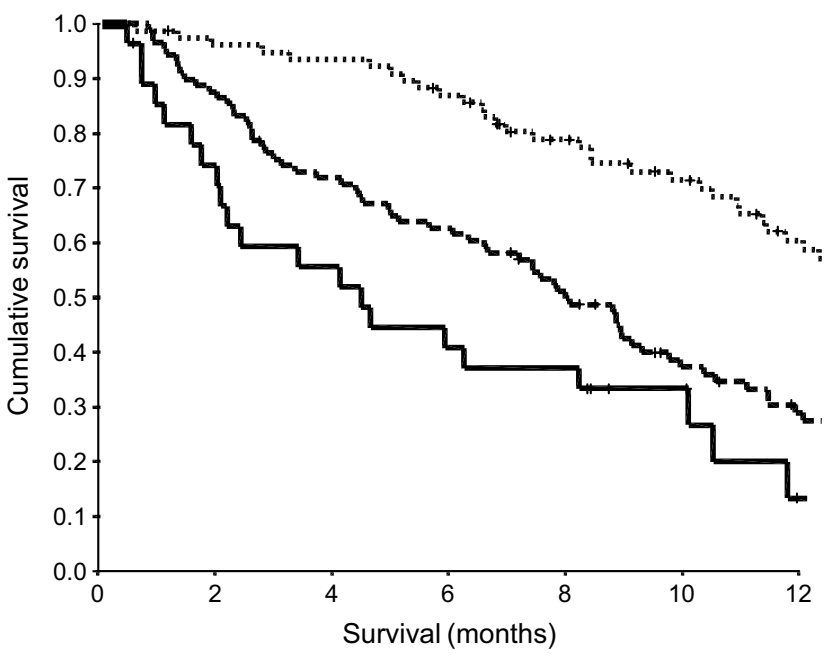

Figure 2 The relationship between an inflammation-based prognostic score (GPS, 0, 1, 2 from top to bottom) and survival in patients with inoperable gastro-oesophageal cancer receiving active treatment.

Table 2 Clinical characteristics and cancer-specific survival in patients with inoperable gastro-oesophageal cancer: multivariate survival analysis

\begin{tabular}{|c|c|c|c|}
\hline & Patients $(n=258)$ & Hazard ratio $(95 \% \mathrm{Cl})$ & $P$-value \\
\hline Sex (male/female) & $166 / 92$ & $1.07(0.80-1.45)$ & 0.642 \\
\hline Tumour site (oesophagus/gastric) & $142 / 116$ & $1.36(0.96-1.92)$ & 0.087 \\
\hline TNM stage $(1 / / 1 / 11 / / / \mathrm{V})$ & 29/27/64/138 & $1.55(1.30-1.83)$ & $<0.001$ \\
\hline GPS $(0 / 1 / 2)$ & $92 / 121 / 45$ & $1.51(1.22-1.86)$ & $<0.001$ \\
\hline Alkaline phosphatase $\left(\mathrm{UI}^{-1}\right)$ (Tertiles I/2/3) & $85 / 85 / 84$ & $1.10(0.92-1.32)$ & 0.300 \\
\hline
\end{tabular}

GPS $=$ Glasgow Prognostic score

Table 3 Clinical characteristics and cancer-specific survival in patients with inoperable gastro-oesophageal cancer receiving active treatment: multivariate survival analysis

\begin{tabular}{|c|c|c|c|}
\hline & Patients $(n=195)$ & Hazard ratio $(95 \% \mathrm{Cl})$ & $P$-value \\
\hline Sex (male/female) & $129 / 66$ & $1.14(0.80-1.65)$ & 0.465 \\
\hline TNM stage $(1 / I / / I I / / V)$ & $27 / 20 / 51 / 97$ & $1.66(1.36-2.03)$ & $<0.001$ \\
\hline GPS $(0 / 1 / 2)$ & $78 / 89 / 28$ & $1.75(1.35-2.26)$ & $<0.001$ \\
\hline Alkaline phosphatase $(U / I)($ Tertiles I/2/3) & $67 / 64 / 60$ & $0.97(0.78-1.21)$ & 0.788 \\
\hline
\end{tabular}

GPS = Glasgow Prognostic score. 
Table 4 Clinical characteristics and cancer-specific survival in patients with inoperable gastro-oesophageal cancer receiving supportive treatment: multivariate survival analysis

\begin{tabular}{|c|c|c|c|}
\hline & Patients $(n=63)$ & Hazard ratio $(95 \% \mathrm{Cl})$ & $P$-value \\
\hline Sex (male/female) & $37 / 26$ & $1.17(0.67-2.05)$ & 0.579 \\
\hline Tumour type (adenocarcinoma/squamous) & $45 / 18$ & $0.89(0.39-2.04)$ & 0.785 \\
\hline TNM stage $(I / I / / 11 / / 1 \mathrm{~V})^{\circ}$ & $2 / 7 /|3 / 4|$ & $1.68(1.08-2.64)$ & 0.023 \\
\hline GPS $(0 / 1 / 2)$ & $14 / 32 / 17$ & $1.04(0.72-1.51)$ & 0.824 \\
\hline Alkaline phosphatase $\left(U I^{-1}\right)($ Tertiles I/2/3) & $|8 / 2| / 24$ & $1.36(0.94-1.98)$ & 0.105 \\
\hline
\end{tabular}

GPS $=$ Glasgow Prognostic score.

Table 5 The relationship between stage, the GPS and the 12-month cancer-specific survival rate in patients with inoperable gastro-oesophageal cancer receiving active treatment $(n=195)$

\begin{tabular}{lccc}
\hline & Stage I+II & Stage III+IV & Stage I-IV \\
\hline GPS 0 & $67 \%(n=31)$ & $57 \%(n=47)$ & $61 \%(n=78)$ \\
GPS I & $60 \%(n=10)$ & $25 \%(n=79)$ & $29 \%(n=89)$ \\
GPS 2 & $0 \%(n=6)$ & $12 \%(n=22)$ & $16 \%(n=28)$ \\
GPS 0-2 & $62 \%(n=47)$ & $33 \%(n=148)$ & $40 \%(n=195)$ \\
\hline
\end{tabular}

GPS = Glasgow Prognostic score.

elevated C-reactive protein concentration. This is consistent with the concept that the development of hypoalbuminaemia is often secondary to an ongoing systemic inflammatory response (McMillan et al, 2001; Al Shaiba et al, 2004). Glasgow Prognostic score may thus reflect both the presence of an ongoing systemic inflammatory response (C-reactive protein) and the progressive nutritional decline (albumin) of the patient with advanced cancer.

The mechanism by which a systemic inflammatory response might influence cancer survival in these patients is not clear. However, it may be that the presence of a systemic inflammatory response and the associated nutritional decline (McMillan et al, 1998; Scott et al, 2002) influences tolerance and compliance with active treatment (Bromwich et al, 2004; Forrest et al, 2004).
Indeed, Andreyev et al (1998) reported that the poorer outcome of chemotherapy in advanced gastrointestinal cancer patients with weight loss appeared to be as a result of receiving less chemotherapy, due to toxicity, rather than poorer tumour response.

When the relationship between the GPS and 12-month survival rate was examined in patients with stage III/IV disease receiving active treatment, there was approximately a five-fold decrease in the survival rate between those patients with a GPS of $0(57 \%)$ and those with a GPS of $2(12 \%)$. This suggests that there is a subgroup of patients who derive little survival benefit from active treatment. However, it is important to remember that treatment in these patients is given with palliative intent and survival data do not reflect end points of palliation. This aspect is being explored further in ongoing work, however the identification of a patient subgroup with limited prognosis, through the use of a simple reliable prognostic score, may aid the treatment decision-making process. In particular, it would seem inappropriate to subject such patients to potentially toxic treatments if simpler palliative options exist.

In summary, the prognosis for patients diagnosed with inoperable gastro-oesophageal cancer, even with active treatment, remains poor. The presence of a systemic inflammatory response (an elevated GPS) appears to be a useful indicator of outcome among these patients, independent of stage. Moreover, the GPS has the advantage of being simple to measure, routinely available and well standardised.

\section{REFERENCES}

Allgayer H, Heiss MM, Schildberg FW (1997) Prognostic factors in gastric cancer. Br J Surg 84: $1651-1664$

Al Shaiba R, McMillan DC, Angerson WJ, Leen E, McArdle CS, Horgan P (2004) The relationship between hypoalbuminaemia, tumour volume and the systemic inflammatory response in patients with colorectal liver metastases. Br J Cancer 91: 205-207

Ando M, Ando Y, Hasegawa Y, Shimokata K, Minami H, Wakai K, Ohno Y, Sakai S (2001) Prognostic value of performance status assessed by patients themselves, nurses, and oncologists in advanced non-small cell lung cancer. Br J Cancer 85: 1634-1639

Andreyev HJ, Norman AR, Oates J, Cunningham D (1998) Why do patients with weight loss have a worse outcome when undergoing chemotherapy for gastrointestinal malignancies? Eur J Cancer 34: 503-509

Bromwich E, McMillan DC, Lamb GW, Vasey PA, Aitchison M (2004) The systemic inflammatory response, performance status and survival in patients undergoing alpha-interferon treatment for advanced renal cancer. Br I Cancer 91: 1236-1238

Chau I, Norman AR, Cunningham D, Waters JS, Oates J, Ross PJ (2004) Multivariate prognostic factor analysis in locally advanced and metastatic esophago-gastric cancer - pooled analysis from three multicenter, randomized, controlled trials using individual patient data. J Clin Oncol 22: $2395-2403$
Forrest LM, McMillan DC, McArdle CS, Angerson WJ, Dunlop DJ (2003) Evaluation of cumulative prognostic scores based on the systemic inflammatory response in patients with inoperable non-small-cell lung cancer. Br J Cancer 89: $1028-1030$

Forrest LM, McMillan DC, McArdle CS, Angerson WJ, Dunlop DJ (2004) Comparison of an inflammation-based prognostic score (GPS) with performance status (ECOG) in patients receiving platinum-based chemotherapy for inoperable non-small-cell lung cancer. $\mathrm{Br} J$ Cancer 90: $1704-1706$

Harvey JA, Bessell JR, Beller E, Thomas J, Gotley DC, Burmeister BH, Walpole ET, Thomson DB, Martin I, Doyle L, Burmeister E, Smithers BM (2004) Chemoradiation therapy is effective for the palliative treatment of malignant dysphagia. Dis Esophagus 17: 260-265

Maltoni M, Caraceni A, Brunelli C, Broeckaert B, Christakis N, Eychmueller S, Glare P, Nabal M, Vigano A, Larkin P, De Conno F, Hanks G, Kaasa S, Steering Committee of the European Association for Palliative Care (2005) Prognostic factors in advanced cancer patients: evidencebased clinical recommendations - a study by the Steering Committee of the European Association for Palliative Care. J Clin Oncol 23: $6240-6248$

McMillan DC, Scott HR, Watson WS, Preston T, Milroy R, McArdle CS (1998) Longitudinal study of body cell mass depletion and the inflammatory response in cancer patients. Nutr Cancer 31: 101-105 
McMillan DC, Watson WS, O'Gorman P, Preston T, Scott HR, McArdle CS (2001) Albumin concentrations are primarily determined by the body cell mass and the systemic inflammatory response in cancer patients with weight loss. Nutr Cancer 39: 210-213

Middleton G, Cunningham D (1995) Current options in the management of gastrointestinal cancer. Ann Oncol 6(Suppl 1): 17-25; discussion 25-26

Morgan DB, Hill GL, Burkinshaw L (1980) The assessment of weight loss from a single measurement of body weight: the problems and limitations. Am J Clin Nutr 33: 2101 - 2105

O'Gorman P, McMillan DC, McArdle CS (2000) Prognostic factors in advanced gastrointestinal cancer patients with weight loss. Nutr Cancer 37: $36-40$

Pyrhonen S, Kuitunen T, Nyandoto P, Kouri M (1995) Randomised comparison of fluorouracil, epidoxorubicin and methotrexate (FEMTX) plus supportive care with supportive care alone in patients with nonresectable gastric cancer. $\mathrm{Br}$ J Cancer 71: 587-591

Ross P, Nicolson M, Cunningham D, Valle J, Seymour M, Harper P, Price T, Anderson H, Iveson T, Hickish T, Lofts F, Norman A (2002) Prospective randomized trial comparing mitomycin, cisplatin, and protracted venous-infusion fluorouracil (PVI 5-FU) with epirubicin, cisplatin, and PVI 5-FU in advanced esophagogastric cancer. J Clin Oncol 20: $1996-2004$

Rowland ML (1990) Self-reported weight and height. Am J Clin Nutr 52: $1125-1133$

Scott HR, McMillan DC, Forrest LM, Brown DJ, McArdle CS, Milroy R (2002) The systemic inflammatory response, weight loss, performance status and survival in patients with inoperable non-small cell lung cancer. Br J Cancer 87: 264-267 